\title{
El Consulado en el proceso de independencia de Cartagena de Indias
}

\author{
Ángel Álvarez Romero \\ Catedrático I. B. "Nervión”. Sevilla
}

\begin{abstract}
Este artículo nos presenta cual fue la postura dominante adoptada por el Consulado de Comercio de Cartagena de Indias en el proceso histórico que culminó el 11 de noviembre de 1811 con la independencia absoluta de la ciudad. En él se recogen las veleidades pseudorrevolucionarias que se dieron en los primeros momentos, para adoptar posteriormente una postura defensora a ultranza de la causa realista. Igualmente se especifica la intensa y fecunda labor propagandística llevada a cabo por el Consulado, utilizando la imprenta que había adquirido en 1800, en todo el virreinato. Por último, se hace hincapié en su intervención en los sucesos contrarrevolucionarios del 4 de febrero de 1811 y en la definitiva extinción del instituto consular por decisión de los patriotas o revolucionarios.
\end{abstract}

El Consulado de Cartagena de Indias agrupaba en su matrícula a todos los comerciantes con una posición financiera sólida y de reconocida fortuna, así como a los principales hacendados de la zona. Las limitaciones que establecía su cédula fundacional hacían que el número de sus matriculados fuese reducido, ocupando sus miembros los puestos más importantes y respetados de la comunidad cartagenera. El establecimiento de la institución mercantil era muy reciente comparado con la dilatada presencia de España en las Indias, y cuando aparecieron al calor del siglo los vientos que portaban afanes emancipadores, el Consulado apenas llevaba más de una decena de años de existencia. Por tanto, el difícil, complejo y traumático período de la independencia lo sorprendió aún en plena tarea de obtener su mayoría de edad como institución pública.

La institución mercantil cartagenera constituía un grupo social integrado por un conjunto de personas ligadas por intereses comunes e identificadas en la consecución de objetivos precisos que presentaba, pese a la existencia de discrepancias internas propias en cualquier colectividad, un criterio común ante los problemas que afectaban a la sociedad del momento. Por tanto, vamos a intentar aproximarnos al papel que desempeñó el Consulado en el proceso de emancipación de la gobernación de Cartagena de Indias.

Aunque la mayoría de los comerciantes que pasaban a las Indias lo hacían por un tiempo limitado, regresando a sus lugares de origen una vez concluídos sus negocios en tierras americanas, no obstante, un número 
apreciable de ellos decidían, por distintas causas, afincarse definitivamente al otro lado del Atlántico. ${ }^{1}$ En muchos de estos casos los que tomaban esta decisión se identificaban de forma incondicional con los intereses de la región, de tal forma que en ocasiones limitaban y cuestionaban su apoyo a las autoridades oficiales metropolitanas.

Es sabido que tras la promulgación del Reglamento de Libre Comercio los intereses de la burguesía comercial establecida en los emporios portuarios indianos habían coincidido por distintos motivos con los de la Corona y, por tanto, el maridaje entre ambas partes había sido perfecto. Así, cuando los críticos como Pedro Fermín de Vargas atacan con acritud al Consulado, están expresando su desacuerdo con el sistema del comercio colonial imperante. ${ }^{2}$ Sin embargo, a partir de 1796 , fecha en que se inicia el largo período de las guerras anglo-españolas, esta comunión de intereses sufrió un considerable deterioro.

Mercedes F. Alvarez manifiesta que los comerciantes, tanto peninsulares como criollos, desempeñaron un papel muy importante en los prolegómenos de la independencia de los dominios americanos. Sus miembros, a través de sus Consulados respectivos, se esforzaron en convencer tanto a las autoridades coloniales como metropolitanas de la necesidad de flexibilizar la política comercial con aquellos territorios a fin de superar la lamentable situación que se padecía y conseguir la prosperidad deseada. ${ }^{3}$ Los comerciantes cartageneros también contribuyeron a este afán liberalizador, como lo demuestran los informes, representaciones, memoriales, etc. que, a través del Consulado de Comercio de la ciudad, se elevaron reiteradamente al rey.

\section{Estructura y actuación del Consulado en los inicios del proceso revolucionario}

El Consulado de Cartagena de Indias no mantuvo una postura uniforme a lo largo de todo el proceso revolucionario, sino que su comporta-

1 McFarlane, Anthony:"El comercio exterior del Virreinato de la Nueva Granada: Conflictos de la política económica de los Borbones". Anuario Colombiano de la Historia Social y de la Cultura., núm. 6-7. Bogotá, 1972, pág. 71.

2 McFarlane, Anthony: "Comerciantes y Monopolio en la Nueva Granada: El Consulado de Cartagena de Indias". Anuario Colombiano de la Historia Social y de la Cultura, núm. 11. Bogotá, 1983, pág. 68. Chenu, Jeanne: Problemática del espacio neogranadino en visperas de la Independencia. Barcelona, 1987, pág. 214.

3 Alvarez F., Mercedes: Comercio y comerciantes y sus proyecciones en la independencia venezolana. Caracas, 1984, pág. 38. 
miento se vio afectado por una serie de modificaciones a medida que éste se radicalizaba y sufría un deslizamiento hacía la izquierda. La institución mercantil, en los inicios del movimiento revolucionario, presentó una actitud un tanto ambigua, que, como se evidenciará más tarde, no era compartida por la mayoría de sus miembros. No obstante, transcurrido ese período de euforia que suele acompañar en sus inicios a toda alteración estructural profunda, muchos de sus miembros que habían contemplado con asentimiento, e incluso participado activamente en las irregularidades políticas, reconsideraron su actitud y aquellas veleidades pseudo-revolucionarias quedaron superadas. Así, los matriculados de extracción peninsular que conformaban la mayoría del instituto mercantil percibieron, con ese singular olfato que caracteriza a todos los ciudadanos dedicados a la actividad comercial, que tanto sus intereses materiales como su futuro estaban estrechamente ligados a los de la Corona.

Una de las consideraciones que motivaron la creación de los nuevos consulados indianos fue la de conseguir un pacto político regional con los comerciantes americanos establecidos en regiones estratégicas. El objetivo era evitar la aparición de peligrosos vacíos de poder o tentaciones rupturistas y en la mayoría de los casos se saldó de forma positiva, ya que los Consulados, como en nuestro caso, actuaron como fieles aliados de la causa realista. ${ }^{4}$

Normalizada la situación en el seno de la institución mercantil, los sectores revolucionarios o patriotas que hasta entonces habían mantenido una explicable actitud de reserva ante el comportamiento del Consulado, van a condicionar su opinión a la orientación que éste adoptase ante los acontecimientos que se avecinaban. Las razones que explican la gran preocupación de los partidarios del nuevo orden sobre cual sería la actitud del Consulado son múltiples: el Consulado constituía, sin lugar a dudas, el cuerpo más nutrido y prestigioso de la ciudad, ya que la mayoría de sus matriculados poseían a nivel individual un sólido e indiscutido poder económico que les permitía una amplia capacidad de actuación en los más diversos aspectos de la vida pública; sus miembros disfrutaban de un indiscutido prestigio y ascendiente personal no sólo en la ciudad, sino en toda la provincia de Cartagena; por la intensa labor de propaganda que desplegaban por toda la jurisdicción virreinal a favor de la causa realista; por la

4 Lucena Giraldo, Manuel: “¿Filántropos u oportunistas?. Ciencia y política en los proyectos de obras públicas del Consulado de Cartagena de Indias, 1795-1800”. Revista de Indias, n. ${ }^{\text {195-196. }}$ Madrid, 1992, págs. 628-629. 
ininterrumpida correspondencia "secreta" que tenían con las autoridades tanto coloniales como metropolitanas que se mantenían fieles a Fernando VII, canalizadas en su mayor parte a través de La Habana; por su persistente distribución de circulares a todas sus diputaciones invitándolas a que reconociesen los distintos gobiernos que se sucedían en la Península, e incitando a los súbditos que disfrutaban del fuero del comercio a contribuir con "excitaciones patrióticas" para auxiliar a sus hermanos de España; haciendo circular por toda la jurisdicción del Virreinato todos aquellos documentos oficiales que pudiesen ayudar a la causa realista, etc. ${ }^{5}$

Cartagena de Indias, al igual que el resto de los territorios americanos, recibió con perplejidad y asombro las confusas noticias que llegaban de Europa. En tales circunstancias, a los gobernantes les urgía disponer de un medio de comunicación que les permitiese llevar a la población aquellas noticias que ellos creían necesarias, ya que el tradicional sistema de Bando, realizado a viva voz por el pregonero de la ciudad, se prestaba a múltiples inconvenientes.

Se contaba en Cartagena con una adecuada imprenta, propiedad de su Consulado, adquirida a principios de siglo y que se encontraba desahuciada y arrinconada pese a los ímprobos esfuerzos realizados por la institución mercantil para ponerla en funcionamiento. ${ }^{6}$ Una multitud de percances, animosidades y desbarajustes administrativos impidieron que la imprenta cumpliese los cometidos para los cuales había sido adquirida. La razón se encontraba en que las altas instancias de la Monarquía, incluyendo al Consejo de Indias, habían prohibido rigurosamente la puesta en funcionamiento de la industria impresora cartagenera.

Pese a la terminante prohibición de las autoridades metropolitanas sobre la entrada en actividad de la imprenta consular, los recientes acontecimientos que se habían producido en la Península modificaron dichos presupuestos y le depararon una proyección distinta a la pensada por sus fundadores. Adelantándonos a los acontecimientos diremos que enterado el comisionado de la Junta de Sevilla, don Antonio Vacáro, de la existencia de una imprenta en la ciudad, le comunicó de inmediato al gobernador de la plaza Blas de Soria que realizase las gestiones necesarias para ponerla en

5 Archivo General de Indias (en adelante AGI), Santa Fe, 961. Consulado a José Joaquín Colón, decano del Consejo de Regencia. Cartagena de Indias, 24 de mayo de 1810.

6 Alvarez Romero, Angel: "La imprenta del Consulado de Cartagena de Indias". Temas Americanistas, núm. 11, Sevilla, 1994, págs. 34 y sigs.

7 Ibídem, pág. 39. 
funcionamiento a la mayor brevedad posible. ${ }^{8}$ En su contestación, el gobernador le notificaba que había entrado en contacto con el Real Consulado, su propietario legítimo, ya que costeó de sus fondos la adquisición de la imprenta, a fin de que se reparasen las piezas deterioradas para su más pronta entrada en funcionamiento. ${ }^{9}$

\section{Primera fase revolucionaria}

Un análisis de la situación de la América española en estos momentos nos muestra de inmediato que lo que individualiza a la crisis desencadenada tras la invasión de la Península por las tropas napoleónicas es la presencia de un grupo social con características y, sobre todo, con objetivos bien distintos de los que hasta entonces se habían dado en la realidad americana. Dicho grupo se instituyó en instrumento y portavoz de un proyecto que pretendía la revisión de la situación política imperante en aquellos dominios. La coyuntura temporal exigida para que la operatividad de dicho grupo se hiciese realidad se nos presenta de forma un tanto inesperada, abarcando desde los postreros meses de 1808, una vez clarificada la confusa situación existente en la Península, hasta bien entrado el año de 1810.

Este período será de vital importancia en la gestación de las ideas que más tarde desencadenarán los futuros acontecimientos revolucionarios. $\mathrm{Al}$ mismo tiempo, una observación epidérmica y circunstanciada de estos meses, podría llevarnos a la falsa idea de que la normalidad política era la tónica imperante en Cartagena en cuanto a las relaciones de este grupo revolucionario con las autoridades provisionales de la Monarquía española. Pero si escudriñamos con rigor este período de afasia política en las altas instancias gubernamentales de la Monarquía, no lo catalogaremos como un homenaje a la utilidad del tiempo por el tiempo. Por contraste, apreciamos que durante esos meses, el grupo discrepante con el sistema político existente, va a ir creando el ambiente propicio hasta alcanzar el punto nodal que le permitirá el control del poder político de Cartagena.

En coherencia con todo lo expuesto manifestaremos que en Cartagena se vivió desde finales de 1808 hasta los primeros meses de 1810 una calma contenida, pues si bien el pueblo permanecía al margen de cualquier acti-

8 AGI, Santa Fe, 745. Vacáro a Blas de Soria. Cartagena de Indias, 19 de octubre de 1808.

9 Ibídem. Blas de Soria a Vacáro. Cartagena de Indias, 1 de septiembre de 1808. Para la puesta en uso de la imprenta, véase mi trabajo ya citado. 
tud amenazadora, las clases que dirigirán y canalizarán el proceso revolucionario no dosificaban sus esfuerzos para crear el ambiente idóneo donde fuese posible la concreción de sus proyectos. Según la fructifera intuición de Burkhardt, "el cuestionamiento radical del orden constituido no se debe buscar entre las clases más desfavorecidas, sino en aquellas que poseen una visión más realista sobre su ascenso social y político".

Por tanto, pese a esta aparente calma, en la ciudad se gestaba una atmósfera de tensión a la que nos hemos referido, en la cual se pondría a prueba la solidez del edificio acosado y las energías de las nuevas fuerzas que ambicionaban imponerse. Aunque el "hecho revolucionario" aún no había alcanzado en Cartagena los niveles de estrado, sí percibimos sus manifestaciones de inquietud en las plazas y calles, pero sobre todo en las peculiares tertulias cartageneras, convertidas en verdadero pulso de la ciudad. ${ }^{10}$

Entre las múltiples Juntas defensoras de los legítimos derechos de Fernando VII que salpicaban el suelo peninsular, fue la establecida en Sevilla el 27 de mayo de 1808 la que se abrogó la representación nacional en nombre del ausente monarca. Actuando como órgano gubernativo central de todos los súbditos de la Monarquía que no reconocían la legalidad ni la legitimidad del gobierno de José I, comenzó a desarrollar una intensa actividad de gobierno destacando entre sus decisiones la designación de una serie de comisionados para las distintas provincias indianas. ${ }^{11}$ El objetivo central de estos comisionados a Indias era intentar conseguir que los súbditos ultramarinos proclamaran su fidelidad a Fernando VII, declarasen la guerra a Francia, conocieran el armisticio firmado con Inglaterra, prestasen su reconocimiento a la Suprema Junta de Sevilla y procurasen recaudar la mayor cantidad de caudales para hacer frente a los gastos que demandaba la guerra contra los franceses. ${ }^{12}$

El elegido para desempeñar esta misión en el virreinato de Nueva Granada fue el capitán de fragata de la Real Armada don Antonio Vacáro, el cual desembarcó en Cartagena de Indias el día 8 de agosto de 1808. Portador de la real provisión emanada de la Suprema Junta de Sevilla, se presentó de inmediato al coronel Blas de Soria, gobernador interino de la

10 Ibídem. Pedro Alvarez, obispo electo de Popayán, al Consejo de Regencia. Cartagena de Indias, 20 de noviembre de 1810.

11 Ibídem. Suprema Junta de Sevilla a Napoleón I. Alcázar de Sevilla, 6 de junio de 1808.

12 Ibídem. Vacáro a Blas de Soria. Cartagena de Indias, 9 de agosto de 1808. 
provincia de Cartagena desde el fallecimiento de su antecesor don Anastasio Cejudo el mismo año. ${ }^{13}$ Los hechos se sucedieron a un ritmo vertiginoso debido a las estrechas instrucciones que llevaba Vacáro de la Suprema Junta de Sevilla, siendo la más importante aquella en la que se instaba a todas las instituciones de la ciudad y provincia a su más pronto reconocimiento. ${ }^{14}$

Tras informar a Blas de Soria de la situación en que se encontraba la Península, de las intenciones de la Junta de Sevilla, y de las medidas que se debían adoptar en Cartagena, tales como la puesta en funcionamiento de la imprenta, todo parecía marchar de acuerdo con los objetivos que se había fijado el comisionado. El gobernador convocó y presidió el día siguiente las Juntas de Guerra y Hacienda y el Cabildo de la ciudad. ${ }^{15}$ Reunido el Ayuntamiento el día 10, en sesión extraordinaria, presidida por el mismo, se fijó para el día 14 la convocatoria de todo el pueblo cartagenero para solemnizar y oír la proclama y jura de la ciudad, en prueba de la fidelidad que ofrecía a Fernando VII. Por contraste, la institución municipal cartagenera mostró ante la propuesta del comisionado Vacáro una actitud circunspecta respecto a las exigencias de la Junta de Sevilla. Sin llegar a una terminante negativa, su contestación rigurosamente meditada posponía de inmediato la ceremonia de reconocimiento de dicha Junta.

Sus argumentos se sustentaban en que la provisión que se le había presentado no disponía textualmente que se realizase la jura y, además, no se tenía la certeza de que dicho reconocimiento lo hubiesen formalizado todos los Cabildos de la Península. Continuaba exponiendo la institución municipal cartagenera que era lógico que se abstuviera de dar dicho paso sin recibir las órdenes de la máxima autoridad del Reino, ya que lo natural era que el reconocimiento de la Junta de Sevilla por el Cabildo de la ciudad viniese precedido por el del virrey. Concluía puntualizando que las reales

13 Pumar Martínez, Carmen: Don Antonio Amar y Borbón último virrey del Nuevo Reino de Granada. Borja (Zaragoza),1991, pág. 172. El fallecimiento de Cejudo, conocedor a la perfección de la realidad americana, fue un contratiempo en aquellos delicados momentos. El era el interlocutor que podía atemperar el choque entre los intereses de la burguesía y los del gobierno central.

14 AGI, Santa Fe, 745. Vacáro a Blas de Soria. Cartagena de Indias, 18 de agosto de 1808. Le notificaba lo perjudicial que resultaba para la causa legítima la reticencia del Cabildo de la ciudad a reconocer a la Junta de Sevilla, ofreciendo a las autoridades de la fragata inglesa "Sabrina", anclada en el puerto, la existencia de un vacío de poder.

15 Ibídem. Blas de Soria a distintas instituciones de Cartagena. Cartagena de Indias, 9 de agosto de 1808. Se intentaba conocer cual era el estado en que se encontraban las Cajas Reales, por cierto en la mayor indigencia. 
órdenes manifestaban muy expresamente que no se llevasen a cabo actos de esta naturaleza si no eran previamente autorizados por la superior autoridad del Reino. ${ }^{16}$

La reacción del comisionado Vacáro fue de manifiesta contrariedad, responsabilizando a Blas de Soria de los contratiempos que habían surgido, como persona en "quién concurren buenos deseos, pero no el talento y la energía que exige su encargo, ni el tino con que es necesario dar a los negocios en las críticas circunstancias actuales, porque la debilidad de su carácter conocida por los Capitulares de este Ayuntamiento, no de buenas ideas, aumenta la influencia de éstos, sumamente perjudicial en los negocios del día, por la malignidad que aparece en sus opiniones". ${ }^{17}$

Ante tan inesperado contratiempo el comisionado le propuso, con insistencia, al virrey que la solución más conveniente sería la de sustituir a Blas de Soria en la gobernación de Cartagena, sugiriéndole al comandante de la comisión hidrográfica don Joaquín Fidalgo como la persona más idónea para el desempeño de tan delicado cargo. Tal sería su acaloramiento y estado de irritación que llegó a proponer a Amar que la solución más adecuada sería que "los Capitulares y el Teniente de Gobernador fueran enviados a la Junta de Sevilla en partida de registro para cortar el mal de raíz". ${ }^{18}$ El Ayuntamiento de Cartagena de Indias se mantuvo impertérrito en su opinión, y sólo reconoció la soberanía de la Junta de Sevilla el 5 de septiembre de 1808, una vez que lo había realizado la Junta creada en Santa Fe, el 21 de agosto, en sesión presidida por el virrey don Antonio Amar y el comisionado Sanllorente, enviado a dicha ciudad por la Suprema Junta de Sevilla. ${ }^{19}$

\section{Jura del cuerpo consular a la Junta de Sevilla}

Las autoridades cartageneras señalaron una fecha a cada institución de la ciudad para que se realizasen los actos de reconocimiento de la soberanía interina de la Suprema Junta de Sevilla. Al Consulado, como una de las instituciones más representativas de Cartagena, se le asignó la del 17 de

16 Ibídem. El Cabildo de Cartagena a Vacáro. Cartagena de Indias, 24 de agosto de 1808.

17 Ibídem. Vacáro a Suprema Junta de Sevilla. Cartagena de Indias, 24 de agosto de 1808.

18 Ibídem. Vacáro a virrey Amar. Cartagena de Indias, 25 de agosto de 1808. de 1808 .

19 Ibídem. El Cabildo de Cartagena a Blas de Soria. Cartagena de Indias, 27 de octubre 
agosto para efectuar dicha ceremonia. En la convocatoria realizada por la secretaría del Gobierno se cometió la irregularidad de dirigirla al Consulado de Comercio de Cartagena de Indias, ignorando que en dichas instituciones mercantiles se daban dos autoridades distintas y, por tanto, la mencionada ceremonia debía celebrarse de forma desglosada. ${ }^{20}$ La razón que justificaba dicha distinción estribaba en que las funciones y responsabilidades de cada una de ellas —el Tribunal Consular o de Justicia y la Junta de Gobierno - eran autónomas e independientes entre sí. ${ }^{21}$

Dentro de la institución consular existía un cierto malestar contra el gobierno central, motivado por una serie de razones a las que ya hemos hecho referencia y entre las que predominaban las de índole economica. ${ }^{22}$ Por tanto no debe extrañarnos que en el mismo seno del Consulado existiese un indeterminado número de matriculados que creían que había llegado el momento oportuno para corregir los defectos que se encontraban pendientes de estudio.

Previamente la Junta de gobierno consular se reunió para preparar tanto el desarrollo de los acontecimientos como los temas que serían debatidos el día 18 y que posteriormente veremos reflejados en el acta de dicha sesión. En el punto cuarto de la misma se contemplaba que los miembros del Tribunal consular se responsabilizarían de que la real provisión emanada de la Junta de Sevilla y "el oficio exhortatorio se difundiera por toda la jurisdicción del Virreinato a través de las diputaciones consulares y demás individuos que se hacen necesarios para ayudar a dicha misión". Al mismo tiempo se invitaba a todos los individuos que estaban en posesión del fuero del comercio a que prestasen la mayor ayuda posible ante las difíciles circunstancias que soportaba la Monarquía española en Europa. ${ }^{23}$ En su punto quinto creemos apreciar una actitud prudente o recelosa. Si entre los distintos

20 Ibídem. El Tribunal consular y Junta de gobierno a Blas de Soria. Cartagena de Indias, 18 de agosto de 1808 .

21 AGI, Santa Fe, 957. Real cédula de erección del Consulado. Madrid, 14 de junio de 1795 La Junta de gobierno del Consulado estaba compuesta por el Tribunal de justicia — prior y los dos cónsules_, más los nueve consiliarios, el síndico, los funcionarios de tiempo o técnicos — contador, secretario y tesorero- y el gobernador de Cartagena, que era su presidente nato, en función del cargo político que desempeñaba en la plaza.

22 Las continuas irregularidades a que a partir de 1796 se vio sometida la política comercial con las colonias, como la inseguridad en el Atlántico, la alternancia de autorizaciones y suspensiones del comercio de neutrales, el cierre de puertos americanos, etc., contribuyeron a que muchos comerciantes se distanciaran del gobierno al creer que éste no defendía bien sus intereses.

23 AGI, Santa Fe, 745. Acta de la Junta de gobierno del Consulado de Cartagena celebrada el 18 de agosto de 1808. Cartagena de Indias, 18 de agosto de 1808. 
encargos que la Junta de Sevilla le había encomendado al comisionado Vacáro ocupaba un lugar prioritario la recaudación de caudales, es lógico que las mayores expectativas recayesen sobre la institución consular que acogía en su matrícula a los vecinos más pudientes de Cartagena. La respuesta que acuerdan los miembros de la Junta de gobierno está en la línea de la más genuina lógica de los ciudadanos dedicados a la actividad mercantil. Ante una situación al menos confusa, pensaron que la postura más razonable sería demorar cualquier compromiso de inmediato y esperar una mayor clarificación de las circunstancias existentes. Así le contesta al comisionado que todos sus miembros estaban prestos a colaborar, pero que "después de madura reflexión habían llegado a determinar que sería más rentable esperar la llegada del buque de guerra que se anunciaba, ya que entonces se le sacaría mejor partido y los donativos serían más cuantiosos". ${ }^{24}$

Al mismo tiempo la situación en la que se veía el gobernador Blas de Soria era muy expuesta e insegura. El comisionado Vacáro le culpaba ante las autoridades superiores, tanto coloniales como metropolitanas, de ser el principal responsable del rumbo que habían tomado los acontecimientos. Consciente de su precaria situación, el gobernador recurrió a todos los medios a su alcance para intentar mejorar su deteriorada imagen. ${ }^{25}$ Prueba evidente de su situación era el acoso y hostigamiento que encontramos hacia su cargo y persona. La doblez e incongruencia del virrey Amar queda patente en que, con fecha 14 de septiembre de 1808, le comunica que su comportamiento "era arreglado a la razón" y que "así se debía actuar en momentos de tanta gravedad", para a los cinco días, por superior decreto, separarlo del mando general interino de la ciudad, que puso a disposición del brigadier don Antonio de Narváez, dejándole solamente con el militar de la Plaza, es decir de "murallas para dentro", ${ }^{26}$ que iba anejo a su cargo de teniente de rey. ${ }^{27}$

24 Ibídem. Acta de la Junta de gobierno celebrada en Cartagena de Indias el 18 de agosto de 1808 y Vacáro a la Junta de Sevilla. Cartagena de Indias, 1 de octubre de 1808.

25 Ibídem. Blas de Soria a la Junta de Sevilla. Cartagena de Indias, 20 de septiembre de 1808. Le comunica a las autoridades centrales que está cumpliendo estrictamente todas las providencias de Vacáro. Puntualiza que el pueblo está perfectamente informado por medio de la imprenta y envía un ejemplar del primer número del periódico los "Avisos de Cartagena" a fin de precaver la malicia de los que debían dar mejores ejemplos.

26 Ibídem. Instancia del asesor del Cabildo de Cartagena al ministerio de Estado y Hacienda. Cartagena de Indias, 13 de octubre de 1808.

27 Ibídem. Blas de Soria a la Suprema Junta de Sevilla. Cartagena de Indias, 1 de enero de 1808. El mando se lo confió imprudentemente a su amigo don Antonio de Narváez, nacido en la misma Cartagena, donde residían la mayoría de sus parientes y amigos. 
Respecto al Consulado adelantaremos que dicha institución mantenía la misma postura que al conocerse los sucesos de 1808. Aunque todavía en el seno de la población cartagenera no se había producido la ruptura abierta en dos partidos, ya se perfilaba la institución mercantil como el núcleo aglutinador de todos los ciudadanos que se oponían, o se iban distanciando del que "intuían" como proyecto revolucionario. Al mismo tiempo, dentro de la politización generalizada que afectaba, en mayor o menor grado, a todos los elementos de la sociedad cartagenera, el Consulado contaba con la importante baza de ser el propietario legal de la imprenta.

Tal era la importancia de la industria impresora que hasta el más superficial de los observadores podía apreciar los esfuerzos que realizaban las distintas tendencias políticas existentes por hacerse con su control para utilizarla en beneficio de sus intereses. Así, la minoría burguesa cartagenera que aspiraba a orquestar los acontecimientos revolucionarios, la precisaba para poder desarrollar una intensa campaña informativa con explícita proyección proselitista.

El año de 1809 va a transcurrir en Cartagena de Indias dentro de una aparente normalidad, pero en su transcurso se gestará la decisiva crisis de 1810 y los dos grupos existentes van a iniciar una toma de posiciones. Los partidarios del establecimiento de una nueva ordenación política de marcada tendencia autonomista en la ciudad intentarán encontrar en el Cabildo el instrumento adecuado para alcanzar sus objetivos. ${ }^{28}$ Así, mientras los criollos agrupados en torno a la figura de José María García de Toledo, líder dilecto de la burguesía cartagenera en estos primeros tiempos, aspiraban a hacerse con el control de la institución municipal, los partidarios de la causa realista lo hacían en torno al gobierno de la ciudad. No obstante, su gobernador don Francisco Montes, catalogado como una reliquia godoista, careció de la virtualidad necesaria para hacerse con el dominio de la situación, e incluso se malquistó el apoyo de muchos realistas, que verían con agrado su separación del gobierno.

\section{Creación de la Junta de Gobierno de Cartagena de Indias}

El 29 de enero de 1810, el Supremo Consejo de Regencia, a tenor de las inquietantes noticias que llegaban a la Península procedentes de los dominios americanos, resolvió enviar a aquellos territorios comisarios

28 Pumar Martínez, Carmen: Don Antonio Amar ..., pág. 172. 
regios para analizar y aconsejar a las autoridades indianas sobre los problemas existentes. El 8 de mayo, procedentes de Caracas, arribaron a Cartagena don Antonio de Villavicencio y don Carlos Montúfar. El primero de ellos, designado para resolver los problemas concernientes al virreinato de la Nueva Granada, inició de inmediato las gestiones ante el gobernador Montes y el Cabildo de Cartagena para conseguir el más pronto reconocimiento del Consejo de Regencia. ${ }^{29}$

El gobernador, tras manifestar que estaba dispuesto a materializar dicho acto, convocó un Cabildo para el 12 de mayo, a fin de llevar a cabo dicho cometido. El líder insurgente, José María García de Toledo, haciendo gala de sus grandes dotes políticas, en una habilísima intervención oratoria pidió el establecimiento de una Junta de Gobierno en la ciudad de Cartagena. Para él, el reconocimiento de la legitimidad de Fernando VII y de la soberanía del Consejo de Regencia pasaba por la erección de la mencionada Junta.

La justificación de su petición se podría recoger en la frase "porque este Cuerpo establecido legalmente y por los sufragios del público, era el más competente para entender y deliberar en las ocurrencias del día". Por tanto, apoyándose en una parte de los miembros del Cabildo, rehusó admitir los ofrecimientos del comisionado regio si con anterioridad no se aceptaba su proyecto y proponía la convocatoria de un "Cabildo abierto", a fin de conocer la voluntad popular sobre los graves problemas que se debatían. ${ }^{30}$

El 22 de mayo de 1810 fue la fecha en la que la Junta de Gobierno de Cartagena de Indias quedó definitivamente estructurada. Presidido el Cabildo por el asesor del Gobierno Múnive y Mozo, y con la asistencia del comisionado don Antonio de Villavicencio, se desarrolló en un ambiente tenso y de gran efervescencia, y se corria el riesgo de no adoptarse ninguna solución definitiva. ${ }^{31}$ En este estado de cosas emitió su "voto" don Antonio

29 Lemaitre, Eduardo: Historia General de Cartagena. Bogotá, 1983, Vol. III, pág. 7. Villavicencio, criollo aristócrata nacido en Quito, era descendiente de cartageneros, ya que su abuelo fue el primer marqués de Premio Real.

30 Gómez Hoyos, Rafael: La independencia de Colombia. Madrid, 1992, pág. 139.

31 Porras Troconis, Gabriel: Documentos concernientes a los antecedentes de la declaración absoluta de la independencia de la provincia de Cartagena. Cartagena de Indias, 1930, pág. 38. A la sesión del 22 de mayo asistieron: alcaldes ordinarios: García de Toledo y Díaz Granados. Regidores: Tomás Andrés de Torres, Salvador Narváez, José María del Castillo, Germán Gutiérrez de Piñeres, José A. Fernández, Lázaro M. Herrera, José A. Amador, José M. Múnive, Santiago González, Santiago de Lecuna, Francisco del Fierro, Juan V. Romero, M. Demetrio de Vega y José M. del Real, siendo el síndico procurador José Antonio Ayos. 
de Narváez, primer regidor de la ciudad y diputado a Cortes quien, centrando el debate, hizo posible que se pudiese abordar de una forma concreta el problema del establecimiento de la Junta de Gobierno de la ciudad.

Su razonamiento se asentaba en que los proyectos de reforma propuestos en días anteriores deberían ser respetados y manifestaba que, dadas las circunstancias imperantes, no se debería chocar con "el concepto que ya ha adoptado el pueblo en los días 16 y 17 con las manifestaciones de alegría, vivas, músicas, sobre el establecimiento de una Junta de Gobierno". Como podemos observar, el brigadier, con la experiencia acumulada a lo largo de sus más de cincuenta años de vida pública, recurre constante que acompañará a todas las decisiones políticas importantes de este período- a la presión popular fácilmente manejable en una sociedad tan sensitiva como la cartagenera de principios del XIX.

Como fundamento jurídico legal va a recurrir a la "ley 2. título 7, libro 4. de las Municipales que ordena que sean los corregidores con los Cabildos los que se hagan cargo de una gobernación interina, y debe ponerse en observancia por ser consecuente con la Real Orden de 31 de enero de 1810 en la que se dispone la supresión de todas las Juntas que no fuesen superiores". Proponía que el ejercicio de gobierno se llevase "a socio" entre el gobernador y el Cabildo, depositando éste su autoridad en una delegación para la mayor agilización de los asuntos de gobierno. El gobernador ejercería la administración de justicia entre partes, quedando los asuntos más graves como competencia exclusiva del Cabildo. ${ }^{32}$

Una vez aprobada la creación de la Junta de Gobierno, el Cabildo designó por unanimidad a don Antonio de Narváez y la Torre, primer regidor de la corporación municipal, y a don Tomás Andrés de Torres, uno de los más destacados miembros del Consulado, quienes acompañarían al gobernador Montes como coadministradores en la Junta de Gobierno de Cartagena. ${ }^{33}$ Como última formalidad, todos los asistentes a tan histórica sesión procedieron a jurar el cumplimiento de las nuevas formas de gobierno "acomodadas en cuanto es posible a la necesidad y a las leyes". A esta fase del proceso revolucionario se le ha venido a denominar como "revuelta de los letrados" ya que fueron juristas los que llevaron el peso de la

32 AGI, Santa Fe, 745. Voto que adoptó el brigadier de los Reales Ejércitos don Antonio de Narváez y la Torre en la sesión del Cabildo de 22 de mayo de 1810.

33 Ibídem. Tomás Andrés de Torres al Consejo de Regencia. Cartagena de Indias, 11 de noviembre de 1810 . Torres era uno de los regidores añales del Cabildo, y fue nombrado a instancia del gobernador Montes. 
misma. ${ }^{34}$ Los sucesos de mayo, que concluyeron con la deposición de Montes, parecen demostrar que dicha medida era la mejor solución para superar la crítica coyuntura a la que se enfrentaba Cartagena.

No obstante al ambiente de euforia que dominaba la ciudad y al estado de ánimo reinante en muchos que consideraban la caída de Montes como una conquista política, los sucesos debieron despertar recelos entre los miembros de la institución mercantil. Así, el Consulado, dos días después de la deposición del gobernador, elevó un escrito donde hacía pública su más entera fidelidad al Consejo de Regencia. Igualmente ponía singular énfasis en resaltar que había sido el primer Cuerpo de la ciudad en prestar el requerido juramento, ajustando en todo su proceder a las recomendaciones contenidas en la real cédula de 5 de febrero de 1809 y en la real orden de 24 del mismo mes y año.

Entre los principales protagonistas que llenan esta agitada época encontramos al comerciante cartagenero Tomás Andrés de Torres. Su residencia de más de 35 años en la ciudad de la bahía, donde había desempeñado numerosos cargos públicos, le hacía moverse por el quehacer de la ciudad sin extrañar su oriundez. Cuando la Corona erige en 1795 el Consulado de Comercio y selecciona por primera y única vez los cargos de la institución consular, escoge para llenar el puesto de prior, el cargo de máxima importancia, a Tomás Andrés de Torres, lo que deja entrever que su prestigio había desbordado el ámbito comercial cartagenero, llegando a las altas instancias gubernamentales.

Dicho personaje sintetiza de forma objetiva los hechos del 22 de mayo alejándose de cualquier desviación partidista. Dice que "aquel arbitrio se propuso para restablecer la tranquilidad del pueblo que estaba commovido contra el mismo Montes". Igualmente, en la declaración jurada que redacta para justificar su actuación en tan delicados momentos, vuelve a insistir que "se depuso a Montes para la tranquilidad del pueblo, y se actuaron siempre los expedientes justificativos del comportamiento del Cabildo". ${ }^{35}$

34 Gómez Hoyos, Rafael: La independencia de Colombia, pág. 140. Elías Ortiz, Sergio: Historia Extensa de Colombia, Bogotá, 1971, Tomo IV, pág. 131. Entre los miembros de las "profesión legal" que participaron en dichos acontecimientos encontramos a Manuel Díaz Granados, José María del Real, José María del Castillo, Germán Gutiérrez de Piñeres y José María García de Toledo.

35 AGI, Santa Fe, 745. Cartagena de Indias, 11 de noviembre de 1810. Tomás Andrés de Torres redactó de su puño una "Representación para el presidente de la Suprema Junta de Gobierno de Cartagena", en la cual fundamenta su desacuerdo con el resto de sus compañeros de Junta, hecho que invalida cualquier opinión sobre la parcialidad del informante. Rubricada en sus cuatro páginas, fue depositada ante el escribano real don Agustín Gallardo. 
Por tanto interpretamos tan trascendentales acontecimientos como una forma de acabar con la tensa atmósfera existente entre españoles y americanos.

Las autoridades de la Regencia tuvieron conocimiento del desarrollo de estos sucesos políticos a través del comisionado regio, testigo de excepción de tan importantes acontecimientos. En las inmediatas fechas de 24 y 29 de mayo, Villavicencio envió a las autoridades metropolitanas un descarnado informe denunciando la deplorable situación en que se encontraba el virreinato. Para la elaboración de ambos escritos, exponía Villavicencio que el Consulado había sido uno de los cuerpos que mejor le había informado. ${ }^{36}$

Ante la reticencia de Montes a aceptar el sistema de cogobierno aprobado por el Cabildo, éste, asegurada la neutralidad de las fuerzas armadas, se reúne el 14 de junio para condenar la actitud obstruccionista del gobernador. Llamado por la institución municipal el teniente de rey, Blas de Soria, se le confirió posesión del gobierno, arrestándose seguidamente al depuesto Montes, que días más tarde sería embarcado hacia La Habana. ${ }^{37}$ Pese a tan drásticos arbitrios, la situación política no había remitido, persistiendo los encrespados ánimos en la ciudad. Evaluando tan incontrolada tensión que amenazaba con estallar en cualquier momento, el comisionado regio Antonio de Villavicencio se dirige a las autoridades del Consejo de Regencia advirtiéndoles que "sólo la llegada del virrey electo Francisco X. Venegas podría salvar a aquellos dominios de la tormenta que le amenazaba". ${ }^{38}$

Dos meses más tarde, el 14 de agosto de 1810, se organizó la "Suprema Junta Provincial de Cartagena de Indias", eligiéndose como presidente por cuatro meses a García de Toledo. Como podemos deducir

36 AGI, Santa Fe, 629. Memorial del comisionado regio don Antonio de Villavicencio, elevado al Consejo de Regencia. Cartagena de Indias, 24 de mayo de 1810. El memorial recogía con minuciosidad muchos de los aspectos revisables de la sociedad colonial, tales, ocupación de cargos públicos, educación, comunicaciones, impuestos, rapacidad de los funcionarios, indios, estancos, etc.

37 AGI, Santa Fe, 745. "Representación...", de T.A. de Torres. Cartagena de Indias, 12 de noviembre de 1810. Tras la expulsión del gobernador Montes, la Junta de Gobierno de Cartagena quedó integrada por Blas de Soria, como presidente interino; T.A. de Torres y José María del Real, que había sustituido a don Antonio de Narváez por enfermedad. Porras Troconis, Gabriel: Documentos concernientes ..., pág. 39. Los jefes militares que se presentaron al llamamiento fueron los comandantes del fijo, de Artillería, del apostadero de Marina y los tenientes coroneles de las milicias pardas y blancas.

38 Ibídem. Villavicencio al Consejo de Regencia. Cartagena de Indias, 6 de junio de 1810. 
existía una gran reticencia entre los revolucionarios a que se pudiera constituir un fuerte poder unipersonal en la Provincia. ${ }^{39} \mathrm{Al}$ mismo tiempo, los acontecimientos que se desarrollaban en el resto del territorio neogranadino contribuyeron a deteriorar el "entendimiento" que se había dado entre la institución mercantil y los elementos revolucionarios. Los sucesos acaecidos y las decisiones adoptadas en Santa Fe, produjeron un fuerte impacto en la ciudad cartagenera. La Suprema Junta de Gobierno establecida en la antigua capital virreinal, reunida el 26 de julio de 1810, decidió romper cualquier lazo que la vinculase con la soberanía que representaba el Consejo de Regencia, al mismo tiempo que decidía no admitir el nombramiento del virrey electo don Francisco Venegas. Con este objeto, enviaba instrucciones al gobierno de Cartagena para que impidiese la entrada del mencionado virrey en el Reino. ${ }^{40}$

Testimonian la existencia de dicha influencia en las autoridades cartageneras las distintas informaciones recibidas al respecto en el Consejo de Regencia. Entre ellas encontramos la carta enviada el 1 de septiembre por el comandante general del Istmo, don Juan de la Mata, en la que notifica que "Cartagena había seguido el mismo camino de Santa Fe, pero lo hace con la solapa de reconocer a nuestro legítimo Rey y a V.M". ${ }^{41}$

El problema más acuciante que se les presentaba a las autoridades de la Suprema Junta de Gobierno de Cartagena era la inminente llegada del virrey electo. La razón de dicha inquietud radicaba en que la Regencia, por real orden de 25 de agosto, había desaprobado el comportamiento del Cabildo en los sucesos que llevaron a la separación de Montes, ordenando que se volviese a la forma de gobierno que existía anteriormente. Por tanto, si se acataba el juramento realizado por el Cabildo el 17 de mayo, por el cual se reconocía la soberanía de la Regencia, no quedaba otra alternativa que admitir la presencia del virrey don Francisco Venegas, so pena de incurrir en la ilegalidad. ${ }^{42}$

39 Sourdis de la Vega, Adelaida: Cartagena de Indias durante la Primera República. Bogotá, 1988, pág. 34. La Suprema Junta estaba compuesta por el Cabildo en su totalidad, es decir doce concejales, más seis diputados elegidos por el pueblo y los delegados de los municipios de Mompóx, Tolú, San Benito Abad y Simití.

40 AGI, Santa Fe, 745. Acta de la sesión de la Suprema Junta de Gobierno de Santa Fe, 7 de julio de 1810. Tras la extinción de los tribunales superiores de Santa Fe, se creo la Suprema Junta de Gobierno de la Provincia de Cartagena de Indias, ocupando su presidencia José María García de Toledo.

41 Ibídem. Juan de Mata al Consejo de Regencia. Panamá, 1 de septiembre de 1810.

42 Ibídem. Tomás Andrés de Torres al Consejo de Regencia. Cartagena de Indias, 3 de noviembre de 1810 . 
Previéndose de un momento a otro la mencionada contingencia, se reunió el Cabildo el 30 de agosto, a fin de decidir la postura que se iba a adoptar ante tan urgente problema. Tomás Andrés de Torres refiere que tras una acalorada sesión, en la cual, incluso los más flemáticos de sus vocales le impidieron exponer su opinión, decidieron unilateralmente y sin consultar a otras Juntas de las establecidas en el Virreinato, ni a las corporaciones y tribunales existentes en la ciudad, enviarle una diputación notificándole que se volviese a la Península. ${ }^{43}$

Como hemos visto, la determinación adoptada por los miembros de la Suprema Junta de Gobierno no respondía a los fundamentos contenidos en el reconocimiento jurado y publicado solemnemente por el Cabildo, el 17 de mayo, del Consejo de Regencia. La toma de esta resolución motivó la dimisión del presidente interino de la Junta, Blas de Soria, el cual fue sustituido por Múnive y Mozo, abrogándose de inmediato José María García de Toledo todas las facultades de gobernador comandante general y dejando sólo los asuntos relativos a lo contencioso en manos del teniente de gobernador y los coadministradores.

Tomás Andrés de Torres expondrá en su declaración secreta que a partir de aquel momento todos los vocales lo miraban como sospechoso, "excusándome darme conocimiento de los asuntos de gobierno como a los demás". Que no abandonaba su puesto de gobierno "ya que me expondría a perder mi libertad y mis bienes, con desamparo de mi numerosa familia, sino de mi vida". ${ }^{44}$

Aunque la actitud de los revolucionarios aparecía nítida, motivos de distinta índole aconsejaron a sus líderes continuar preservando de forma capciosa el reconocimiento oficial de la soberanía del Consejo de Regencia. No obstante, la situación era tan evidente, que tras la prohibición de la entrada del virrey electo en Cartagena, fueron muchos los realistas que pidieron sus pasaportes, entre ellos Blas de Soria, ya que a nadie se le ocultaba el rumbo que tomarían los acontecimientos. ${ }^{45}$

43 Ibídem. Exposición de los sucesos relativos al rechazo del virrey Venegas relatados por un protagonista tan relevante en todos los acontecimientos del momento como Tomás Andrés de Torres.

44 Urueta, José P.: Cartagena y sus Cercanías. Cartagena. 1886, págs. 99 y 100. Cfdo. Lemaitre, Eduardo: Historia General de Cartagena, tomo III, pág. 10. Para valorar hasta qué punto la Suprema Junta era un instrumento del Cabildo, recordamos que en ella, dos miembros — Blas de Soria y Tomás Andrés de Torres- eran partidarios de recibir al virrey.

45 Nieto. Juan José: Geografía Histórica local de Cartagena. República de Nueva Granada descrita por Cantones. Cartagena, 1839, pág. 41. 


\section{Difícil situación de la Junta de Gobierno.- Actividades propagandistas del Consulado}

Pese al absoluto control que ejercían los elementos revolucionarios sobre la Suprema Junta de Gobierno de Cartagena, ésta se hallaba en una posición difícil e incómoda derivada de su decisión de reconocer de forma ficticia la soberanía del Consejo de Regencia. ${ }^{46}$ Tan incongruente situación le proporcionaba a la institución mercantil un asidero legal que le permitía desarrollar con impunidad sus actuaciones en pro de la causa realista.

Como veremos, la actuación del Consulado no se limitaba al reconocimiento de la autoridad del Consejo de Regencia, sino que por el contrario, testimoniaba su fidelidad desarrollando una intensa y activa campaña propagandística en favor de la deteriorada causa realista. El Consulado, merced a la eficiente utilización de su imprenta, desempeñó un papel informativo y propagandístico de primerísimo orden.

Su intensa actividad no se circunscribía al reducido ámbito provincial, sino que llegaba, a través de la utilización de sus más de veintiséis diputaciones esparcidas por todo el territorio de la Nueva Granada, a los más distantes lugares. Como recoge Lucena Giraldo, la cédula de erección, en su artículo X, le concedía la cobertura legal necesaria para intervenir en todo el virreinato, a excepción de las provincias de Quito y Popayán. ${ }^{47}$ Quizás, lo más positivo de su labor fue el proporcionar testimonios documentales sobre el verdadero desarrollo de los acontecimientos que se producían en el seno de la Monarquía española. Las impresiones de los discursos, manifiestos, proclamas, etc., desmontaba muchas de las deformaciones informativas que propalaban los elementos revolucionarios. ${ }^{48}$

Como prueba de la fidelidad y anhelo patriótico que se respiraba en el seno de la institución consular recogemos algunas de las decisiones de su Junta de gobierno. Contando con la anuencia general de sus miembros, se comprometió a sufragar los gastos relativos a la reimpresión de 30 nuevos ejemplares de la real orden de 1 de noviembre de 1808, comunicada por

46 Fray Custodio, obispo electo de Popayán, al Consejo de Indias.La Habana, 15 de marzo de 1813. Arrazola, Roberto: Documentos para la Historia de Cartagena de Indias. Cartagena, 1963, pág. 25.

47 Lucena Giraldo, Manuel: “¿ Filántropos ...”, pág. 63.

48 AGI, Santa Fe, 1016. Acta de la elección consular correspondiente a 1810. Cartagena de Indias, 4 de enero de 1810. Cada dos años eran renovados los comerciantes que ocupaban las diputaciones que el Consulado tenía en toda la jurisdicción del Nuevo Reino. En esta fecha alcanzaba el número de 26 diputaciones. 
don Pedro Cevallos, primer secretario de Estado nombrado por la Suprema Junta Central, en la que se recogían todos los hechos ocurridos desde el 19 de marzo de aquel año para que fuesen distribuidos por todas las diputaciones consulares. ${ }^{49}$ Igualmente se decide publicar y distribuir por el virreinato, utilizando a los individuos que gozaban del fuero del comercio, la real cédula que disponía la expulsión de los extranjeros y genízaros. ${ }^{50}$

A medida que los acontecimientos europeos alcanzaban mayor tensión, la actividad propagandística del Consulado adquiría mayores proporciones a fin de contrarrestar las falsas noticias que de forma encubierta, o bien manipulada, llegaban del otro lado del Atlántico. Los primeros meses de 1810 se caracterizaron por su acentuada fiebre impresora. Así, la Junta de gobierno resolvió imprimir para que circulasen por toda la jurisdicción consular, la real orden de 24 de febrero de 1810 sobre la instalación del Consejo de Regencia, el "Discurso de su decano don José Joaquín Colón", la "Proclama del Supremo Consejo de Regencia a los americanos", con el Decreto de la convocatoria a Cortes de 14 de febrero de 1810, y la "Proclama hecha por la Junta Superior de Cádiz", remitida por su presidente Francisco Venegas, que posteriormente sería electo virrey de Nueva Granada.$^{51}$ La proyección y eficacia propagandística de la institución mercantil debió ser extraordinaria y, posiblemente, su potencia de actuación subterránea contra el gobierno revolucionario crearía en éste no pocas reticencias.

Como hemos dicho, la finalidad prioritaria de su labor tendía a que en la Nueva Granada los súbditos ultramarinos no dudasen de la existencia real de los distintos gobiernos que se sucedían en la Península, desmintiendo la campaña desatada por los insurgentes de que la causa de la Monarquía Española se encontraba totalmente arruinada. Al mismo tiempo dicha información coadyuvaba a impulsar el espíritu de patriotismo existente e incitaba a colaborar en las suscripciones patrióticas voluntarias para hacer frente a los cuantiosos gastos que exigía la lucha contra los franceses..$^{52}$

49 AGI, Santa Fe, 1133. Cuentas del Consulado de Cartagena de Indias de 1808. Cartagena de Indias, 4 de mayo de 1809. Alvarez Romero, Angel: "La imprenta en Cartagena durante la crisis de la independencia” en Temas Americanistas, núm. 12. Sevilla, 1995, pág. 20.

50 Ibídem. El importe alcanzado fue de 38 pesos, 4 reales.

51 AGI, Santa Fe, 961. El Tribunal del Consulado al Consejo de Regencia. Cartagena de Indias, 25 de mayo de 1810. El citado tribunal consular estaba integrado por J.I. de Pombo, Teodoro María Escobar y Santiago de Lecuna.

52 Ibídem. El Consulado al Consejo de Regencia. Cartagena de Indias, 1 de noviembre de 1811. 


\section{1.-Reacción e Independencia}

Desde finales de 1810 las posiciones políticas de las distintas tendencias revolucionarias se fueron clarificando y los comportamientos más o menos ambiguos que habían imperado hasta entonces se verán desplazados por actitudes más trasparentes. No obstante, los insurgentes mantenían encontradas y constantes agresiones verbales que ahondaban las profundas grietas que los escindían. Por lo que hace a los elementos realistas de la ciudad cartagenera, asistimos a un proceso de similar naturaleza, pero sus partidarios van a formar un bloque monolítico en el cual estarán integrados todos los individuos refractarios al nuevo orden de cosas.

Los elementos militares y civiles de la ciudad, partidarios de la causa realista, iniciarán una serie de actuaciones para intentar corregir la situación existente en Cartagena. ${ }^{53}$ Para dirigir dicha conspiración se contaba con casi la totalidad del cuerpo de oficiales del Fijo, destacando entre los comprometidos a Juan Esteban de León y a Miguel Gutiérrez. Para conocer los contactos que existieron entre el elemento militar y el civil contamos con el informe elaborado por el oidor de la Real Audiencia de Santa Fe, don Joaquín Carrión Moreno, que al hacer una exposición de los hechos, puntualiza la existencia de contactos entre ambos elementos que estaban en desacuerdo con la situación imperante en la ciudad..$^{54}$ La mayor parte de los ciudadanos comprometidos en la conspiración pertenecían al gremio de los mercaderes catalanes, poseedores de las mejores pulperías de la ciudad, que formaban entre ellos una compañía cuyo número no bajaba de cincuenta y que se habían distinguido por su eficacia en ocasiones anteriores. ${ }^{55}$

Igualmente, poseemos el valiosísimo informe, elaborado personalmente por el capitán del Fijo Miguel Gutiérrez, máximo responsable de los sucesos del 4 de febrero. Su relato coincide con el del oidor Joaquín Carrión, aunque apenas hace referencias a los contactos habidos con la población civil de Cartagena. A grandes rasgos expone los acontecimientos:

"que el Regimiento se había quedado sin sus Jefes naturales, y la Suprema Junta de Gobierno resolvió que recayese el mando sobre el Teniente Coronel del Auxiliar de

53 Alvarez Romero, Angel: "La imprenta de Cartagena ...”, pag. 18.

54 AGI, Santa Fe, 747. Informe del oidor Joaquín Carrión. La Habana, 3 de marzo de 1811. Dicho informe fue redactado con los testimonios de los pasajeros de la goleta "Nuestra Señora del Carmen" que acababa de atracar procedente de Cartagena. Ibídem, pág. 35.

55 AGI, Santa Fe, 744. Expediente del gobernador sobre los pulperos catalanes afincados en Cartagena de Indias. Cartagena, 23 de diciembre de 1805. 
Santa Fe, José Moledo. Reunidos todos los oficiales representamos a través del Comandante General don Antonio Narváez nuestra disconformidad por distintas razones destacando entre otras el haber colaborado en la destitución del Virrey ..., como la Junta seguía manteniéndolo decidimos para el día 4 de febrero por la mañana, salir en armas el regimiento. Aquella mañana, a las ocho, fui llamado a la puerta del cuartel por el regente de la Audiencia José María García de Toledo quién utilizando como pretexto que Narváez requería mi comparecencia decidió apartarme del regimiento cosa que no consiguió lograrlo... Vuelto al cuartel y referido lo acontecido, llegamos al acuerdo que era la ocasión de liberar a la Patria y hacer reconocer los derechos de Fernando VII. Iba a la cabeza de la tropa, cuando soy detenido por Narváez que nos preguntó que queríamos y contestamos todos fuera la Junta y que se pusiese el gobierno en manos del Teniente de Rey y que se jurasen las Cortes. Su contestación fue publicar un bando imponiendo por el Rey pena de vida a los individuos que estaban en formación que no obedeciesen la orden de retirarse al cuartel:separada la tropa de las armas pasamos a las Casas del Cabildo, donde se me previno que el pueblo pedía mi cabeza, y era cierto, ya que el pueblo amotinado la pedía reiteradamente, al igual que quienes eran los agentes que los promovían". ${ }^{56}$

Tras el fracaso del intento contrarrevolucionario aumentó la crispación entre los patriotas, debido a las discrepancias existentes sobre la actitud que se debería adoptar contra los que de alguna manera habían estado involucrados en la intentona golpista. ${ }^{57} \mathrm{La}$ tendencia jacobinista que acaudillaban los Piñeres, empecinada en llevar el proceso revolucionario a sus últimas consecuencias, se convirtió en celadora del nuevo orden, a costa de imponer un despotismo arbitrario e incoherente con el genuino programa revolucionario preconizado por la burguesía criolla de la ciudad. La pérdida paulatina del control de los dirigentes piñeristas sobre la indigente plebe de color degeneró en una situación cercana a la anarquía. La misma crispación de ánimos existente en la ciudad cartagenera, va a predisponer al sector revolucionario más extremista a liquidar la engañosa situación imperante y acelerar el proceso que conduciría a la independencia.

No obstante, el Consulado continuará en su actitud de defender el orden jurídico legalmente constituido, pese a ser conscientes del peligro que suponía apoyar a ultranza la causa realista.$^{58}$ Así, en carta de 31 de ene-

56 AGI, Santa Fe, 747. La Habana, 3 de marzo de 1811. Lemaitre, Eduardo: Historia General..., vol. III, pág. 17.

57 AGI, Santa Fe, 657. Informe de Ventura Pascual Ferrer sobre la situación de la ciudad. Cartagena de Indias, 10 de abril de 1811. Manifiesta que la actuación de las tropas el 4 de febrero sin un plan preconcebido ha traído la opresión a todos los individuos honrados de la ciudad.

58 El año de 1811, el Tribunal consular estaba constituido por J.Vicente Romero Campos, Antonio Sarriá y Santiago González, prior y cónsules respectivamente. 
ro de 1811, comunican a las autoridades de la Regencia que habían reconocido las Cortes generales y extraordinarias ateniéndose estrictamente a los términos recogidos en los decretos de 25 y 27 de septiembre de 1810 , ordenando a sus ministros y dependientes que realizasen, como estaban obligados, el mencionado juramento. ${ }^{59}$

En la misma carta de enero de 1811, el Consulado le remitía al Consejo de Regencia el acta que le pasó el presidente de aquella Junta Provincial en la que constaba haberse llevado a cabo el reconocimiento de la Regencia pero con "ciertas restricciones", al considerarla como una "Soberanía interina y supletoria". ${ }^{60}$ Ya en el contexto de la misiva se dejaba entrever que las autoridades revolucionarias pensaban que el Consulado se plegaría a sus sugerencias, cosa que éste no aceptó, haciendo el reconocimiento de las Cortes tal como venía ordenado en el real decreto de 24 de septiembre de $1810 .{ }^{61}$ Los revolucionarios, por primordiales razones de índole internacional, pese a que su actitud capciosa no engañaba a nadie, seguían manteniendo su reconocimiento a las Cortes españolas, aunque conceptuándolas como "una soberanía interina y supletoria".

Espectadores de la profunda división que reinaba en las filas revolucionarias, los dirigentes de la institución consular percibieron que era el momento más oportuno para intensificar la campaña propagandística. ${ }^{62}$ Poniendo de manifiesto una vez más su acendrado patriotismo, solicitaban de las autoridades metropolitanas el envío urgente de todas las órdenes, decretos y proclamas, e incluso retratos de los soldados más distinguidos, a fin de mantener vivo el patriotismo que se iba diluyendo por momentos. Subrayaban con especial hincapié el envío de las Gacetas oficiales y de los Diarios de Cortes, a fin de que nadie pudiera dudar de la existencia de las autoridades peninsulares y deshacer la maliciosa propaganda difundida por los insurgentes de que toda la Península había sucumbido ante los ejércitos napoleónicos.

Desde el fracaso contrarrevolucionario del 4 de febrero de 1811 hasta el 30 de junio de 1812, fecha en la cual quedó extinguido el Consulado, el instituto mercantil va a ir perdiendo paulatinamente su capacidad operativa.

59 AGI, Santa Fe, 961. El Tribunal del Consulado al Consejo de Regencia. Cartagena de Indias, 31 de enero de 1811.

60 Ibídem. de 1811 .

61 Ibídem. El Tribunal consular al Ministerio de Hacienda. Cartagena de Indias, 4 de julio de 1811 .

62 Ibídem. El Consulado al Consejo de Regencia. Cartagena de Indias, 31 de noviembre 
Cada vez encontramos menos testimonios de su actividad pública y cuando nos los topamos suelen ir cargados de un fatalismo que denota un estado cercano a la impotencia. Pese a la jura, continúa el Consulado, la Junta Provincial de Cartagena procedía como soberana, así promulgó reglamentos de comercio, extinguió cobros, hizo rebajas en los adéudos de los derechos reales y municipales, que lo recaudado en concepto de subvención de guerra no fuese a la tesorería consular sino a las Cajas reales, etc. ${ }^{63}$

Su situación se hacía por días más precaria e insostenible, llegándose a plantear entre sus miembros el proponer a las autoridades españolas una suspensión temporal de la institución. Debemos tener presente que las decisiones de la Junta de Gobierno consular eran ignoradas por las diputaciones de comercio de Santa Marta y Panamá. Estas, siguiendo las recomendaciones de las autoridades metropolitanas, no enviaban, por prudencia, las cantidades recaudadas por concepto del impuesto de avería ante la posibilidad de que fuesen incautadas por los insurgentes. ${ }^{64}$

Los revolucionarios más extremistas, enojados de tanta actitud ficticia, empujaron los acontecimientos para llegar al presentido final. La llegada a Cartagena, a través de las Gacetas de Jamaica, de los últimos sucesos ocurridos en la Península, sobre todo la toma de Tarragona y el estrecho cerco a que se encontraba sometida la Isla de San Fernando, precipitaron el inevitable final. ${ }^{65}$ La mañana del día 11 de noviembre fue testigo del más ruidoso tumulto que la ciudad había presenciado. Un enorme gentío proveniente del arrabal de Getsemaní, cruzó la puerta que daba a la plaza de la Aduana dirigiéndose a la casa de armas, de la que forzaron las puertas, y ya armado se dirigió a la casa del Gobierno. El gentío, integrado por todas las castas, negros mulatos y zambos, en número siete veces superior a los blancos, pedía con un estrepitoso clamor que se declarase y publicase la independencia. Con una situación de exaltación colectiva, el populacho consiguió que, tras deliberación, la independencia de la provincia de Cartagena fuese publicada a la una de dicho día. ${ }^{66}$

El Gobierno tuvo que acceder a todas las peticiones, de tal suerte que los jefes y cuerpos de la ciudad se vieron obligados sin exclusión a jurar la

63 Ibídem.

64 Ibídem. El Tribunal consular al Ministerio de Hacienda. Cartagena de Indias, 2 de julio de 1811. Se queja de que lo pretendido por dichas diputaciones es sustraerse de su jurisdicción.

65 AGI, Santa Fe, 747. Informe del oidor Joaquín Carrión. La Habana, 3 de marzo de 1811.

66 AGI, Santa Fe, 961. El Consulado de Cartagena al Consejo de Regencia. Cartagena de Indias, 30 de noviembre de 1811. 
independencia ${ }^{67}$ En aquellos momentos, ante la manifiesta superioridad de las castas, en todos los ánimos se cernía el temor de que ocurriesen los sangrientos sucesos de Santo Domingo que tan cuantiosas muertes ocasionaron entre el elemento blanco. ${ }^{68}$

La prolija comunicación que el Consulado dirige a las autoridades metropolitanas, aún en medio de tanto desastre, muestra un hálito de dignidad, pues con manifiesto sentimiento de mortificación, expresan que se avergüenzan de la situación a la que se había llegado, pero llenos de rubor denuncian que, sin armas ni recursos, no han tenido más remedio que someterse. Así, la institución mercantil remite a las autoridades metropolitanas el Acta de independencia publicada por el gobierno insurgente, refiriendo el suceso y la violencia a que fue sometida para prestar su juramento y adhesión al gobierno legítimo. ${ }^{69}$

\section{Extinción del Consulado}

Tras la proclamación de la Independencia, la primera actuación de la Suprema Junta de Gobierno fue la de aprobar las proposiciones presentadas por los diputados del pueblo. Dicho decálogo compendia un esbozo de lo que sería la futura Constitución de la República de Cartagena. En la nueva labor legislativa, muchas de las instituciones existentes serán desmanteladas al no considerarlas de utilidad para el nuevo orden institucional.

El Consulado fue una de las instituciones que con más rigor sufrió la enemistad de los nuevos gobernantes, ya que sus miembros eran considerados como leales partidarios del antiguo orden de cosas. Desaparecida la deferencia formal que las autoridades revolucionarias habían tenido que simular durante meses, las primeras resoluciones fueron las de recortarle sus atribuciones y modificar las normas internas del Instituto. Así, en la resolución séptima del decálogo se recogía que los cargos más importantes

67 Corrales, Manuel Ezequiel: Documentos para la Historia de la Provincia de Cartagena de Indias hoy Estado Soberano de Bolívar en la Unión Colombiana. Bogotá, 1883, vols. I-II, pág. 356. El acta que ratifica la independencia y que fue firmada por todos los miembros de la Junta manifestaba que "La Provincia de Cartagena de Indias es desde hoy de hecho y por derecho Estado libre, soberano e independiente;que se halla absuelta de toda sumisión, vasallaje y obediencia, y de todo otro vínculo de cualquier clase y naturaleza que fuese, que anteriormente la ligase con la corona y gobierno de España”.

68 Ibídem.

69 Ibídem. El Tribunal consular al Consejo de Regencia. Cartagena de Indias, 30 de noviembre de 1811 . 
de la institución mercantil debían recaer en los matriculados de origen americano, que todos los fondos que se encontraban depositados en la tesorería consular pasasen de inmediato a las Cajas oficiales, aunque en concepto de reintegro, sin especificar la procedencia de los mismos, ya fuesen correspondientes a la subvención de guerra, al Departamento de Balanza, e incluso aquellas cantidades destinadas a hacer frente a los pagos de suscripciones u otros gastos propios de una institución de esta naturaleza. ${ }^{70}$

La situación del instituto mercantil no podía ser más anómala ya que sus miembros, la mayor parte de ellos de origen penínsular, se caracterizaban por su afecto a la causa realista. Por otra parte, el Consulado se había convertido en una institución que carecía de miembros suficientes para llenar sus cargos más significativos, por no cumplir los requisitos que recogían las nuevas leyes.

Ante tan insólita y azarosa situación, el gobierno político cartagenero, erigido por sí mismo en República, decidió acabar con tan ficticia situación disponiendo el 30 de junio de 1812 la extinción del Consulado de Cartagena de Indias, tras 17 años de existencia. Difícilmente otra institución encontró peor coyuntura para poder desarrollar los objetivos de potenciación económica de la Nueva Granada, que fueron los que dispusieron para ella sus creadores.

Aunque en 1815, tras la conquista de la ciudad por Morillo, el Consulado cartagenero fue restablecido, su vida fue lánguida e inoperante como la del resto de las instituciones públicas durante este breve período. Bien es sabido que la apuesta de la población americana por un nuevo destino era un hecho irreversible y el Consulado corrió idéntica suerte que la institución monárquica a cuya concesión graciosa había debido su razón de ser.

70 AGI, Santa Fe, 961. Informe del contador del Consulado Alonso Luque. Cartagena de Indias, 2 de julio de 1811. Las deudas del Consulado ascendían a 42.568 pesos, 7 reales. El débito más significativo era el de la sede consular, que alcanzaba 16.400 pesos. 